\title{
Offrir une fleur, offrir sa philia
}

Nikolina Ke[ ${ }^{[1]}$

\section{Résumé}

Il existe dans la céramique attique du VIe et du Ve siècle av. J.-C., un certain nombre d'images où le geste d'offrir une fleur à l'autre se présente comme un moyen de le saluer tout en lui exprimant son estime, sa reconnaissance et son affection. Objet de plaisir à la fois visuel, olfactif et tactile, la fleur est un don qui ravit, capable de nouer ou de renforcer des rapports d'amitié. Ainsi, à l'intérieur des scènes de départ, de rencontre, de retrouvailles et même de réconciliation, la présence discrète de la fleur véhicule-t-elle les notions grecques de philia (amitié) et de charis dans toutes ses déclinaisons: charme, générosité, plaisir.

\section{Oferecer uma flor, oferecer sua philia}

\section{Resumo}

Existe, na cerâmica ática dos séculos VI e V a. C., certo número de imagens nas quais o gesto de oferecer uma flor a alguém se apresenta como uma maneira de saudá-lo, além de expressar sua estima, seu reconhecimento e seu afeto. Objeto de prazer tanto visual, como olfativo e tátil, a flor é um dom que seduz, capaz de atar ou de reforçar os laços de amizade. Assim, em cenas de partida, de encontro, de reencontros e até de reconciliação, a presença discreta da flor remete às noções gregas de philia (amizade) e de charis (amor) em todas as suas declinações: charme, generosidade, prazer.

Palavras-chave: flor; charis; philia.

\section{Ofrecer una flor, ofrecer su philia}

\section{Resumen}

Existen, en la cerámica ática de los siglos V y VI a. C., algunas imágenes en las que ofrecer una flor a alguien se presenta como una forma de saludarlo, además de expresar su estima, su reconocimiento y su afecto. Objeto de un placer a la vez visual, olfativo y táctil, la flor es algo que alegra y es capaz de iniciar o reforzar lazos de amistad. Asimismo, en escenas de partida, de encuentro, de reencuentros o hasta mismo de reconciliación, la discreta presencia de la flor remite a las nociones griegas de philia (amistad) y de charis (amor), en todas sus declinaciones: encanto, generosidad, placer.

Palabras claves: flor; charis; philia.

\section{To offer a flower, to offer your philia}

\begin{abstract}
There is a rather small set of images on attic vases dating from the sixth and fifth century BCE, where the gesture of offering a flower to someone is as a way to salute while expressing his/her esteem, gratitude and affection. As an object of visual, olfactory and tactile pleasure, the flower is a gift that delights, capable of establishing or strengthening relations of friendship. Thus, within scenes of departure, meeting, reunion and even reconciliation, the discreet presence of the flower conveys the Greek notions of philia (friendship) and charis in all its declinations: charm, generosity, pleasure.
\end{abstract}

Keywords: flower; philia; charis 
ur un des côtés de sa célèbre amphore, aujourd'hui au Vatican (fig. 1), Exékias représente une scène familiale : Léda et Tyndare assistent au retour de Castor et de Polydeukès ${ }^{2}$. Parents et fils portent des couronnes végétales, signe de la solennité du moment. Chaque geste esquissé par les figures infuse à la scène de l'intimité et une certaine affection : Polydeukès se penche pour caresser son chien qui se jette sur lui, Tyndare flatte la tête du cheval appelé Kylaros, tandis que Léda lève de sa main droite deux branches et tend de l'autre une fleur à Castor en guise de salutation ${ }^{3}$. Le jeune homme, alors qu'il avance vers la droite, dans la direction de Tyndare, tourne la tête, interpelé par le geste de sa mère à son égard. La fleur, don d'accueil mais aussi, tout comme les rameaux, signe de célébration ${ }^{4}$, figure à mi-distance entre les deux visages de sorte qu'elle attire l'attention du spectateur sur l'échange des regards et très probablement des paroles entre mère et fils : elle est le marqueur de leur rapport mère-fils, de leur philia parentale ${ }^{5}$.
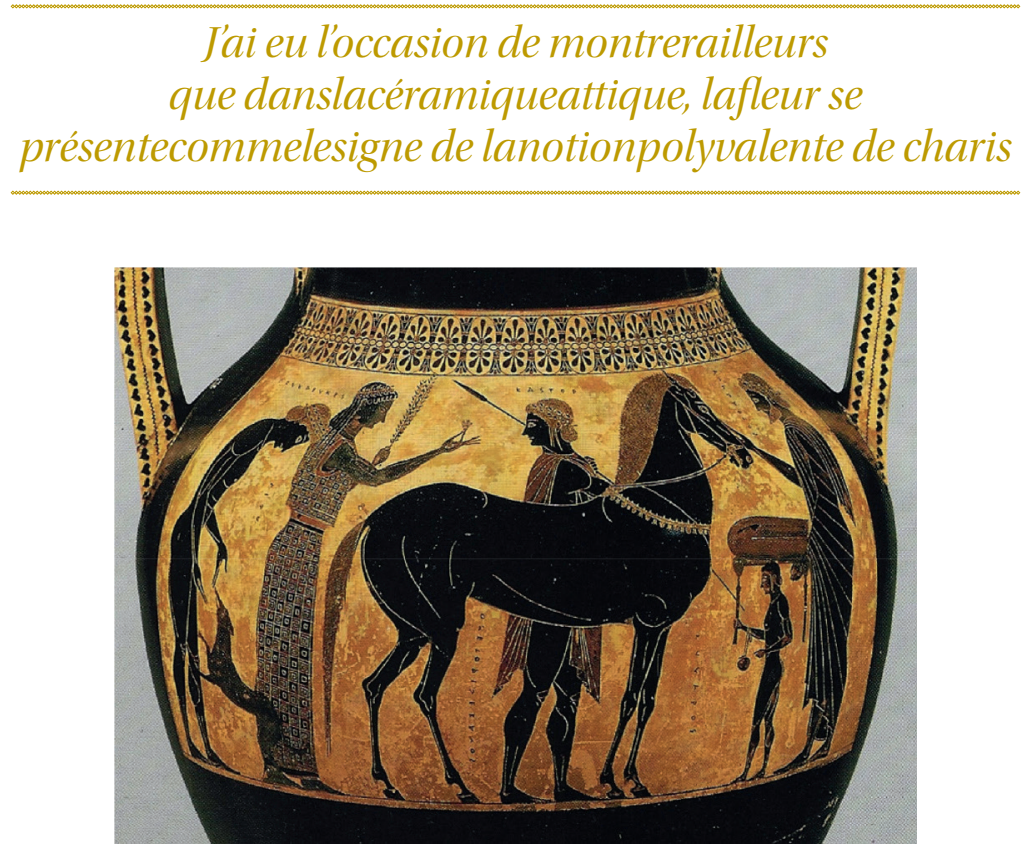

Figura 1

\footnotetext{
${ }^{2}$ Vatican, Museo Gregoriano Etrusco Vaticano 344 ; 540-530 av. J.-C. ; ABV 145.13, 672.3, 686 ; Para 60 ; Add² 40 ; BArch 310395. Pour une analyse complète et un résumé critique de nombreuses interprétations que cette scène a pu inspirer voir Mackay (2010, p. 339-348).

${ }^{3}$ Hermary (1978, p. 51-76 et notamment p. 69), identifie les branches comme des branches de myrte et la fleur comme une rose, les deux végétaux censés être des « symboles d'immortalité ». En dehors du fait que rien, ni dans les textes, ni dans l'iconographie, ne prouve que le myrte et la rose soient des signes d'immortalité, sur les vases attiques, les plantes, les feuillages et surtout les fleurs sont en règle générale trop stylisés et abstraits pour permettre une identification botanique précise. II existe toutefois quelques exceptions, dont le palmier, le lierre, la vigne, parfois le laurier et l'olivier, à savoir des plantes étroitement associées à des divinités d'où le besoin d'être reconnaissables. Sur la difficulté d'identifier les éléments végétaux de notre image, voir Mackay (2010, p. 345).

${ }^{4}$ Offrir des rameaux est une manière de célébrer les qualités à la fois athlétiques, cynégétiques et guerrières des deux jumeaux : sur ces qualités voir Hermary (1978, p. 567-568).

${ }^{5}$ Sur la notion de philia voir ci-dessous n. 8.
} 
J'ai eu l'occasion de montrer ailleurs que dans la céramique attique, la fleur se présente comme le signe de la notion polyvalente de charis $^{6}$ telle qu'elle est incarnée par les trois Charites hésiodiques, Aglaïè, Thaliè et Euphrosynè, évoquant respectivement le rayonnement d'une belle apparence, l'abondance qui appelle à la générosité et à la dépense et enfin, l'allégresse festive ${ }^{7}$. Le plus souvent, la fleur, objet de plaisir à la fois visuel, olfactif et tactile, matérialise la grâce physique, la beauté juvénile et resplendissante en pleine éclosion (anthos hèbès) ainsi que la bonne odeur, composante essentielle de l'attrait physique. En effet, sur les vases attiques de nombreuses figures divines ou mortelles portent des fleurs en dehors de toute tension et intention de mouvement, comme si elles étaient parties intégrantes de leur corps : immobiles et hiératiques, les figures se livrent au regard du spectateur en toute beauté et élégance signalées et rehaussées par les fleurs elles-mêmes. Or, il y a des fois, comme sur l'amphore d'Exékias, où les peintres placent les fleurs au cœur d'une dynamique portée par des gestes de salutation ou d'offrande plus ou moins discrets : tirées de leur inertie de simples parures corporelles, elles se présentent comme les médiateurs et les supports d'une communication, d'un échange contracté entre deux ou plusieurs personnes. Elles sont des dons de choix, dont le charme et le parfum sont capables de ravir et d'invoquer une réaction favorable en retour. Autrement dit, les fleurs peuvent matérialiser une autre forme de charis envisagée moins comme une qualité extérieure que comme une disposition intérieure manifestée à travers le geste du don : cette charis est incarnée par Thaliè. Or, le geste du don est en principe un geste générateur de joie et de plaisir, affects qui sont incarnés par Euphrosynè ${ }^{8}$. Ainsi, les trois déclinaisons de la charis se trouvent-elles réunies dans le geste du don floral.

Plus précisément, les fleurs en tant que dons apparaissent dans trois catégories de scènes : Premièrement, dans des scènes de cour érotique où elles se présentent comme un moyen de séduction et de persuasion. Ensuite, dans des scènes d'offrande cultuelle, où elles sont censées créer et nourrir le lien entre mortels et dieux. Enfin, dans des scènes de départ, de rencontre ou de retrouvailles, moments solennels où le geste de proposer une fleur à l'autre est un moyen de le saluer tout en lui manifestant son estime et sa reconnaissance. Ce même geste peut également exprimer le désir de nouer ou de renforcer des liens de philotês ou philia ${ }^{9}$, ainsi que le plaisir d'être ou de se retrouver avec quelqu'un de cher. C'est cette dernière catégorie de scènes de départ, de rencontre ou de retrouvailles qui retiendra notre attention.

\footnotetext{
'La fleur en tant que signe de la notion polyvalente de charis dans la céramique attique est le thème central de ma thèse de doctorat. Je me permets de renvoyer à mes trois articles sur le sujet (2007; 2008, p. 197-203; et 2015, à paraître).

${ }^{7} J$ e reprend ici l'analyse de Saintillan (2003, p. 541-564) à propos des noms des Charites hésiodiques. Nombreuses sont les études sur la notion de charis, mais il serait impossible de toutes les citer. Je renvoie à titre indicatif à l'étude de MacLachlan (1993) et celle de Azoulay (2004), avec une très riche bibliographie sur les différentes constellations du terme.

${ }^{8}$ A propos du don et de son champ sémantique dans l'antiquité grecque voir Benveniste (1982, p. 315-319 et 1969, p. 81-82). Voir aussi Scheid (1994); Brillante (1998, p. 7-34 et notamment p. 23); et Vidal (1991, p. 30-47).

9Sur la philia comme lien affectif, hospitalité et alliance voir Benveniste (1969, p. 335-353); Taillardat (1982, p. 1-14); et Alaux (1995, p. 199 sq.).
} 
Nous avons vu que sur l'amphore d'Exékias, la fleur que Léda offre à Castor à l'occasion de son retour, opère comme signe de célébration, d'accueil et de philia entre la mère et son fils. On retrouve le même geste dans des scènes de départ. Sur un des côtés d'une coupe d'Oltos (fig. 2), une jeune femme tend une fleur à un guerrier qui s'apprête à partir en compagnie d'autres guerriers parmi lesquels figure Ajax en personne ${ }^{10}$. Si la femme est la mère du guerrier, ce qui n'est pas improbable vu la présence d'un homme âgé un peu plus loin, la fonction de la fleur est celle d'un don d'adieu mettant en exergue le rapport mère-fils. Si, au contraire, il s'agit de son épouse, ce qui paraît plus probable, la fleur pourrait être à la fois un don d'adieu et le signe de leur philia conjugale. Quoi qu'il en soit, le geste de la femme est en écho avec le geste de l'homme âgé, et tous les deux signalent une certaine affectivité dans un moment à la fois solennel et émotionnellement chargé qu'est le départ pour le champ de bataille.

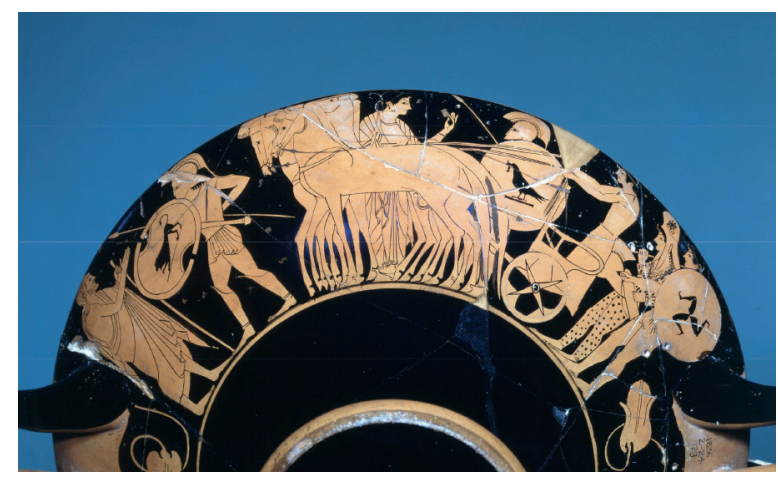

Figura 2

Dans d'autres cas, la fleur marque la philia fraternelle, rapport que l'on ne peut identifier que dans un contexte mythologique : ainsi sur le support d'un cratère, Apollon lyricine salue avec une fleur sa sœur Artémis en train de monter sur son quadrige ${ }^{11}$. Sur une hydrie proche du Peintre de Priam, Apollon lui-même, monte sur un quadrige devancé par sa mère, Léto. Artémis lui tend sa cithare alors qu'Hermès lève de sa main une fleur en signe d'adieu (fig. 3) ${ }^{12}$. Cette image d'ambiance familiale est ainsi marquée par deux éléments aux connotations festives : la cithare, agrément musical, et la fleur, agrément visuel et olfactif, sont toutes les deux des véhicules de plaisir et créatrices d'enchantement.

\footnotetext{
${ }^{10}$ Londres, British Museum E 16 ; 520-510 av. J.-C. ; ARV² 61.75, 1599.14 ; Add² 165 ; BArch 200511.

"Athènes, Musée d’Agora P9275; 500-490 av. J.-C. ; BArch 7833 ; LIMC II, « Artemis», n. 1210, pl. 544. Même si la figure féminine riest pas nommée, la présence d’Apollon, des deux palmiers et de la biche nous font penser à Artémis. Une scène semblable figure sur une « escharis » en terre cuite où Apollon tend une fleur à une déesse montant sur un quadrige en présence d'une seconde déesse et d'Hermès : Eleusis, Musée Archéologique 468 ; Peintre de la fontaine de Madrid ; ABV 335.2; BArch 301823.

${ }_{12}$ Paris, Musée du Louvre F297 ; 520-510 av. J.-C. ; ABV 333.1 ; Add² 91 ; BArch 301808. Les noms sont inscrits au génitif.
} 


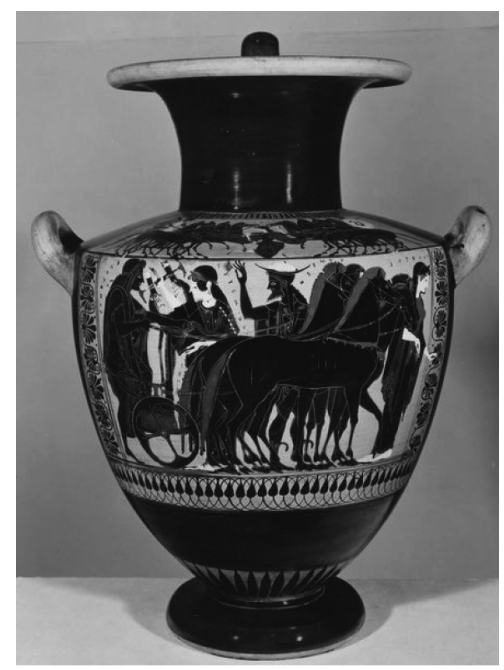

Figura 3

Quelques mots sur Hermès : il est le dieu à la baguette d'opulence et de

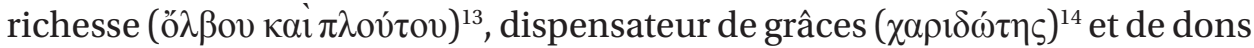

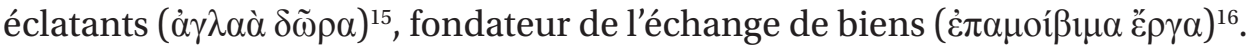
Il sait ravir avec le chant suave de la lyre ${ }^{17}$ et ses paroles douces tandis qu'il se plaît à accompagner les Charites, les Heures, les Muses et les Nymphes dans leurs rondes ${ }^{18}$. Ayant lui-même les traits d'un jeune homme, sa première

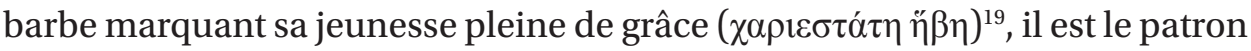
de l'athlétisme et le protecteur de la jeunesse. Incontestablement, les liens d'Hermès avec la charis sont très étroits, c'est pourquoi, de toutes les divinités masculines, c'est lui qui est le plus fréquemment représenté une fleur à la main : la coupe d'Oltos à Tarquinia où le dieu porte de manière ostensible un joli bouton floral, est sans doute l'exemple le plus connu ${ }^{20}$. La charis marque également les rapports à la fois intimes et complexes d'Hermès avec Apollon, scellés par une série d'échanges réconciliateurs. Si Apollon ravit les dieux avec sa musique c'est grâce à la mètis d'Hermès. Avide d'honneurs, timai, le fils de Maïa, a utilisé les deux déclinaisons de la charis, l'euphrosynè et l'aglaïa que le retentissement séducteur de sa lyre/cithare procurait à Apollon afin de lui extraire comme contre-don le kûdos, la gloire ${ }^{21}$. Il est probable que le geste d'Hermès sur l'hydrie du Peintre de Priam soit un écho lointain de cette série d'échanges entre les deux frères.

\footnotetext{
13Hymne homérique à Hermès, I, 529.

${ }^{14}$ Hymne homérique à Hermès, II, 12.

${ }^{15}$ Hymne homérique à Hermès, I, 462

${ }^{16}$ Hymne homérique à Hermès, I, 516-517. Sur le rapport du dieu avec la pratique d’échange voir Kahn (1978, p. 119 sq.) et plus récemment Jaillard (2007, p. 91-95).

${ }^{17}$ Hymne homérique à Hermès, I, 455, $492-495$.

${ }^{18 S}$ ur les représentations d'Hermès accompagné de Charites ou de Nymphes voir LIMC V. S. v. «Hermes », p. 317-318.

${ }^{19}$ Odyssée, X, 278-279.

${ }^{20}$ Tarquinia, Museo Nazionale R66848 ; 510-500 av. J.-C. ; ARV2 60,66 ; Para 327 ; Add2 81 ; BArch 200502.

${ }^{21}$ Hymne homérique à Hermès, 449 et 476-477.
} 
Sur une amphore du Groupe de Léagros (fig. 4) ${ }^{22}$, Hermès tend une fleur vers son autre demi-frère, Dionysos. Celui-ci auréolé de vigne, se tient debout entre deux figures féminines assises alors que plus loin un satyre esquisse un geste d'étonnement. Le don floral avec lequel Hermès salue Dionysos, difficile à distinguer entre le feuillage et les grappes de vigne, fait écho au don que ce dernier apporte à l'humanité, le vin contenu dans le canthare mais aussi dans l'amphore, support de cette image. Hermès, " convive de festins $»^{23}$ s'appropriant souvent les attributs canoniques de Dionysos ${ }^{24}$, est un vrai bon vivant et la fleur dans sa main incarne parfaitement cette joie de vivre ${ }^{25}$.

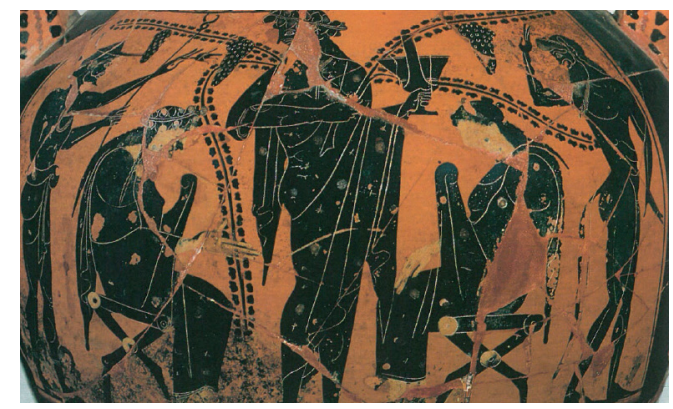

Figura 4

Plus que des liens familiaux, la fleur marque des liens fondés sur une estime et une reconnaissance réciproques. Sur une hydrie du Peintre d'Achéloos (fig. $5)^{26}$, on retrouve Hermès dans son rôle de guide, en grec proegetès, suivi d'une femme brandissant des torches, d'un char et d'un homme barbu. Le dieu vient à la rencontre d'un centaure, en toute probabilité Chiron, qu'il salue avec une fleur ; on dirait même que le dieu insiste à ce que le centaure respire son parfum suave, tellement il l'approche de son visage. Cette image insolite rappelle fortement l'iconographie de la remise d'Achille enfant, à Chiron, sauf qu'ici il n'y a pas d'enfant ${ }^{27}$. Le fait que tous les personnages sont couronnés et que le centaure lève de sa main droite deux branches végétales, crée une ambiance de célébration solennelle. La fleur, signe de reconnaissance à l'égard de ce bon et sage centaure, «éducateur des héros et garant d'une généalogie princière ${ }^{28}$, ne fait qu'à renforcer cette ambiance.

\footnotetext{
${ }^{22}$ Orvieto, Museo Civico, Coll. Faina, 186 ; 520-510 av. J.-C. ; ABV 368.98, 389 ; Para 170.2 ; Add² 98 ; BArch 302093.

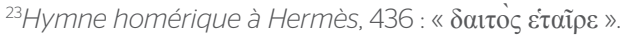

${ }^{24}$ Voir le stamnos du Peintre de Berlin à Paris, Louvre CA944 ; ARV2 207.142, 1633 ; Add2 194 ; BArch 201961.

${ }^{25}$ L'offrande et l'échange des dons étant consubstantiels à la nature du dieu, il est difficile de faire la distinction entre la fleur/attribut du dieu et la fleur/don.

${ }^{26}$ Berlin, Antikensammlung F1900 ; 520-500 av. J.-C. ; ABV 385.27 ; Add²102 ; BArch 302872.

${ }^{27}$ D’après les Archives Beazley en ligne, le personnage avec la fleur est Pélée, ce qui nous paraît étrange, étant donné que les bottes à rabat sont à la fois typiques d'Hermès et rares dans le costume cynégétique. En outre, nous avons vu qu'il est dans les habitudes du dieu d'être en tête de procession et de saluer avec une fleur à la main.

${ }^{28}$ Voir Schnapp (1997, p. 439)
} 


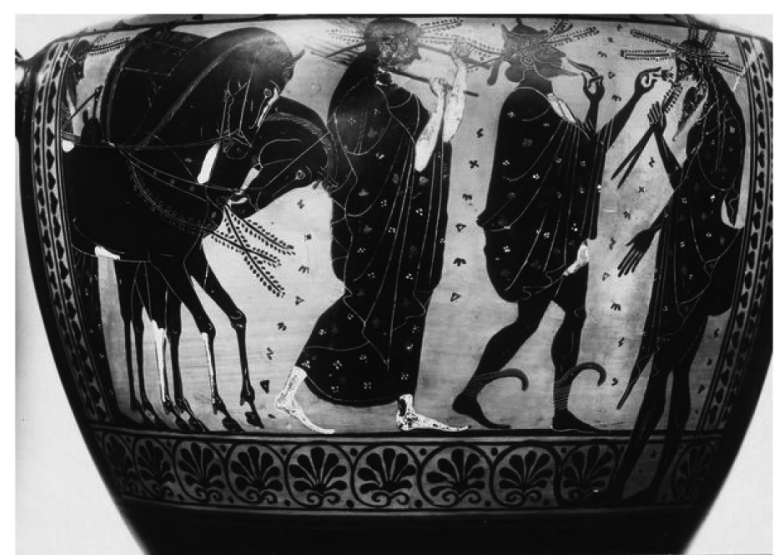

Figura 5

Enfin, sur une hydrie du Peintre de Priam (fig. 6) ${ }^{29}$, c'est Hermès lui-même qui devient le destinataire d'un don floral. Suivi de neuf figures féminines représentées de manière indifférenciée, et de Dionysos, il tourne la tête, interpelé par le geste d'offrande florale que la figure féminine en tête du cortège esquisse à son égard. La fleur qui, très souvent dans la céramique à figures noires, sert de parure corporelle à des divinités à l'identité imprécise telles que les Muses ou les Nymphes, s'attache ici à un geste exprimant la reconnaissance et l'attachement que le cortège collectif ressent pour son guide.

\section{Plus que desliensfamiliaux, lafleur marque desliensfondéssur une estime et une reconnaissanceréciproques}

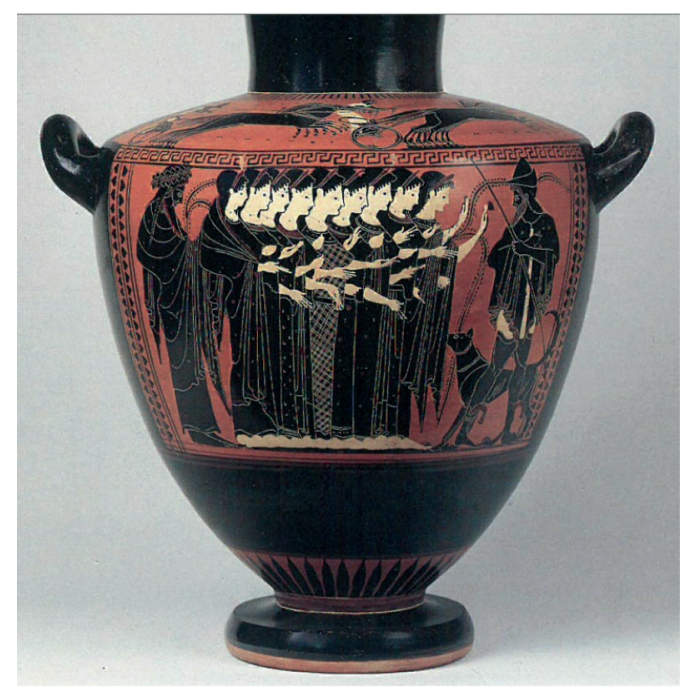

Figura 6 
Dans un esprit beaucoup plus festif et joyeux, on voit sur une coupe du Peintre de Chiusi (fig. 7) ${ }^{30}$, Dionysos sentir la fleur qu'une ménade lui tend. Ce geste est une sorte d'invitation pour que le dieu se réjouisse de la liesse tourbillonnante qu'il inspire chez ses acolytes, ménades et satyres, et qui se manifeste aussi bien à l'intérieur qu'à l'extérieur de la coupe : les branchages et les grappes de la vigne envahissant l'ensemble de la surface du vase, les postures dansantes et les gestes agités du thiase, la poikilia vestimentaire, la polychromie et la pléthore des détails finement incisés créent une ambiance exubérante propre au bien-être dionysiaque.

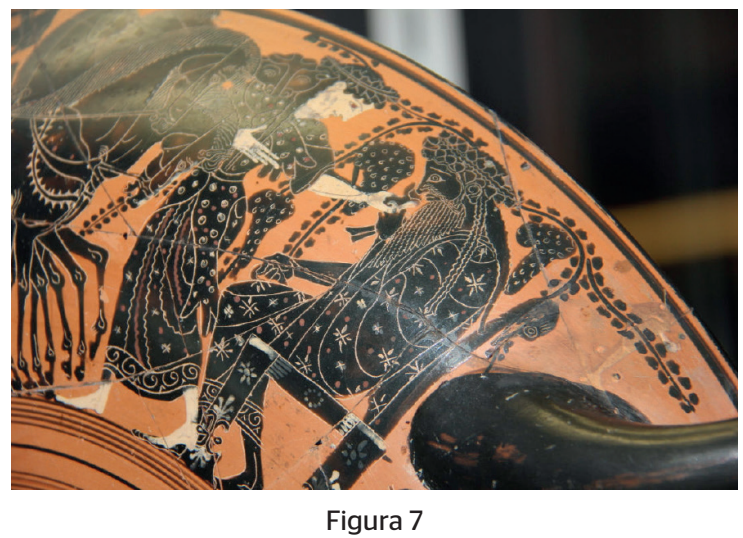

C'est à la fois en tant que don d'accueil et signe de reconnaissance qu'Athéna tend à son protégé, Héraclès, une jolie fleur, sur le côté à figures rouges d'une amphore du Peintre d'Andokidès (fig. 8) d' $^{31}$. Le héros figuré en banqueteur, couronné et luxueusement vêtu, partage enfin les mêmes plaisirs que les Immortels, récompense de son long trajet héroïque : la kliné somptueusement décorée, la table recouverte de mets, les deux vases à boire et la treille infléchie sous le poids de ses branches au riche feuillage et aux grosses grappes étalées autour du héros comme une auréole, donnent un aperçu de cet état de plénitude que seuls les dieux connaissent. La fleur offerte avec autant d'ostentation par la déesse signale qu'Héraclès est maintenant égal aux dieux ; elle est également le signe de cette jeunesse parfaite et inaliénable dont le héros va dorénavant jouir, jeunesse qui est aussi incarnée par sa nouvelle épouse, Hébé.

\footnotetext{
30Paris, Cabinet des Médailles 320 ; 520-510 av. J.-C. ; ABV 389 ; Para 171; Add² 102 ; BArch 302907. ${ }^{31}$ Munich, Antikensammlung 2301 ; 520-515 av. J.-C. ; ABV 255.4 ; ARV22 4.9, 1617 ; Para 113, 320 ; Add² 66, 149 BArch 200009. Le geste d'Athéna rappelle fortement celui de Léda sur l'amphore d'Exékias vue plus haut. Sur le côté à figures noires, attribué au Peintre de Lysippidès, Athéna suivie d'Hermès esquisse un geste de salutation à légard d'Héraclès banqueteur, ce qui démontre que les deux gestes, avec ou sans fleur, sont plus ou moins homologues. Sur la rencontre d'Héraclès et d'Athéna voir Verbanck-Piérard (2006, p. 133-151).
} 


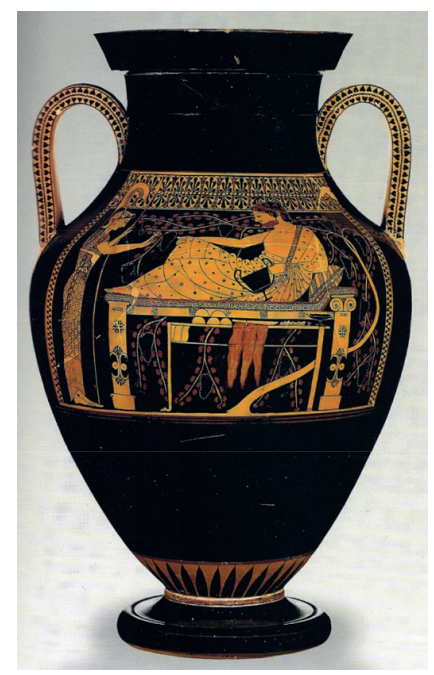

Figura 8

\section{La fleurofferteavecautant d'ostentation par} ladéessesignalequ'Héraclès est maintenantégalauxdieux

Dans le même esprit, une oenochoé attribuée au potier Nicosthénès (fig. 9 ), représente Héraclès flanqué d'Hermès et d'Athéna ${ }^{32}$ : Hermès qui, assure le passage du héros du monde des mortels à celui des dieux, lui adresse un geste de salutation alors qu'Athéna lui tend comme don d'accueil une tige florifère. En réponse, Héraclès tend sa main gauche pour accepter le don. Sur un lécythe à Copenhague, c'est au contraire Héraclès qui tend une fleur à Athéna en présence d'Hermès et d'Iolaos ${ }^{33}$.

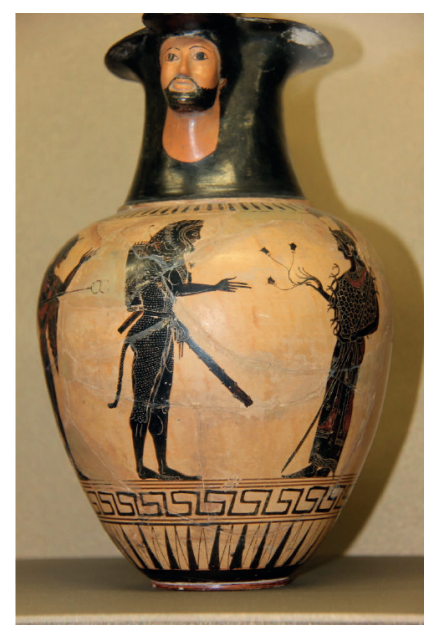

Figura 9

32Paris, Musée du Louvre F116 ; vers 520 av. J.-C. ; ABV 230.2 ; Add² 59 ; BArch 301232.

${ }^{33}$ Copenhague, Thorvaldsen Museum H546; vers 500 av. J.-C. ; CVA Thorvaldsen Museum , pl. 50.41 ; BArch 1012939. 
Le rapport d'affinité entre Athéna et Héraclès est représenté d'une manière davantage démonstrative, sur une oenochoé du Peintre de Gela où la fleur n'est plus portée par un geste mais sert à le mettre en exergue (fig. 10) ${ }^{34}$. On voit le héros tenant de la main droite le poignet droit de la déesse. Ce geste sous-tendu d'un échange de regards, se présente ici comme le signe extérieur d'une relation de confiance mutuelle et d'affectivité réciproque, autrement dit de philia. Le peintre a sciemment marqué ce rapport par une longue tige qui aboutit à une belle palmette, identique à celles du cadre ${ }^{35}$, afin de mieux relever la familiarité affectueuse des deux figures ${ }^{36}$.

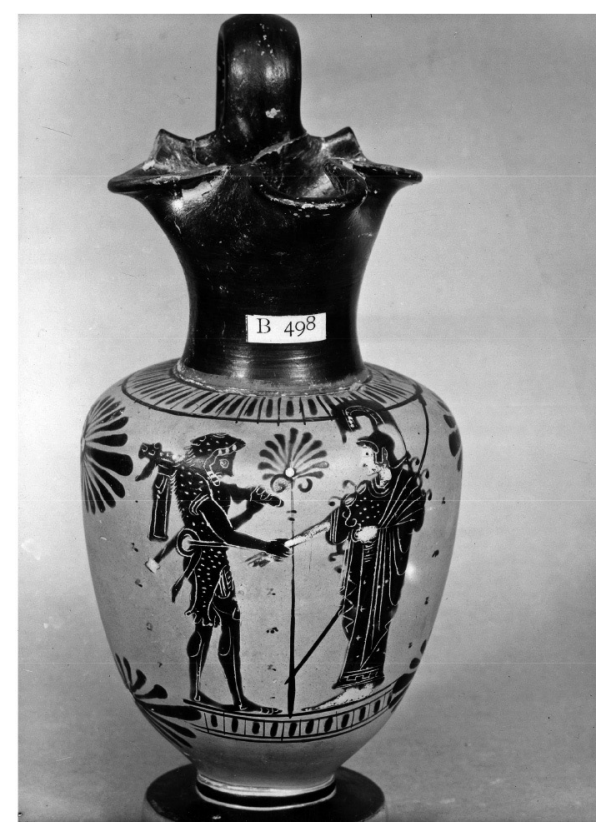

Figura 10

Cette image est assez proche d'une autre du même peintre ornant un lécythe où Héraclès et Athéna, dont on ne voit que les bustes, échangent des regards ${ }^{37}$. Ce tête-à-tête est célébré par une Niké ailée qui, une couronne à la main, volète entre les deux amis. Juste en dessous de la couronne et à mi-distance entre le héros et la déesse, une tige à trois fleurons-palmettes forme une sorte de croix qui souligne le lien interactif entre ces trois personnages. À la droite d'Athéna, une figure féminine, également représentée en buste, est couronnée par une

\footnotetext{
${ }^{34}$ Londres, British Museum B 498 ; vers 500 av. J.C. ; BArch 31867; L LMC V. « Herakles », n. 3184, pl. 142. Pour une histoire du thème de la confrontation d'Athéna et d'Héraclès voir Mommsen (1989, p. 118-145).

${ }^{35}$ Notons ici, qu'une fois insérés dans la scène et en interaction avec les figures, les motifs floraux fonctionnent à la fois comme ornements, agents figuratifs et même comme signes à part entier.

${ }^{36}$ Verbanck-Piérard ( 2006, p. 137). D’après l'auteur, le geste figuré sur l'oenochoé r'est pas une dexiosis mais un cheir' epi karpô, geste qui serait ici sans doute détourné de ses connotations nuptiales. Sur les vases attiques représentant le geste de dexiosis entre Athéna et Héraclès, quelquefois associé à un autel et aux ustensiles de libation voir LIMC V. s. V. «Herakles », p. 150.

${ }^{37}$ Vienne, Kunsthistorisches Museum 84; vers 500 av. J.-C.; BArch 517; LIMC V. « Herakles », n. 3129 ; Thomsen (2011, p. 165-168).
} 
seconde Niké. Nous pourrions penser qu'il s'agit de Hébé que les dieux, ici représentés par Athéna, ont offerte comme épouse à Héraclès une fois que celui-ci a été accepté parmi eux. À la fois épouse et incarnation de la jeunesse éternelle, Hébé est un double don d'accueil à Héraclès, rappel de son nouvel état de dieu. Si cette interprétation est correcte, on aurait une image évoquant les deux formes de philia, celle entre la déesse (et par extension les dieux) et le héros et celle entre ce dernier et sa nouvelle mariée.

Le plus bel exemple d'une philia scellée par une fleur est incontestablement le médaillon d'une coupe de Douris (fig. 11) ${ }^{38}$. La scène rappelle fortement celle qui orne l'oenochoé du Peintre de Gela vue plus haut : Héra trônant, un sceptre à la main, tend une phiale vers Prométhée ayant l'air d'un dieu ; enveloppé dans son himation, il porte une sorte de couronne métallique et tient un sceptre. Entre les deux, il y a tout un jeu de lignes obliques. D'abord, la phiale figure au centre de l'image et plus précisément au point où s'entrecroisent le sceptre de la déesse et celui du Titan ${ }^{39}$. Ensuite, au dessus de la phiale mais toujours au centre de l'image, figurent deux énormes tiges fleuries de type ornemental qu'Héra tient de la même main que son sceptre ; leurs fleurs attirent l'attention du spectateur sur les visages des deux figures tout en les magnifiant. À l'instar du schéma des mains jointes représenté sur l'oenochoé du Peintre de Gela, ce jeu de chiasmes, d'entrecroisements symétriques évoque la nature du lien dorénavant égalitaire entre Héra et Prométhée : dans cet espace qui se referme autour d'eux, la déesse, qui représente les Olympiens, et le voleur de feu se sont enfin réconciliés. La phiale évoquant l'acte de libation et les deux tiges fleuries sont les marques extérieures de cette réconciliation.

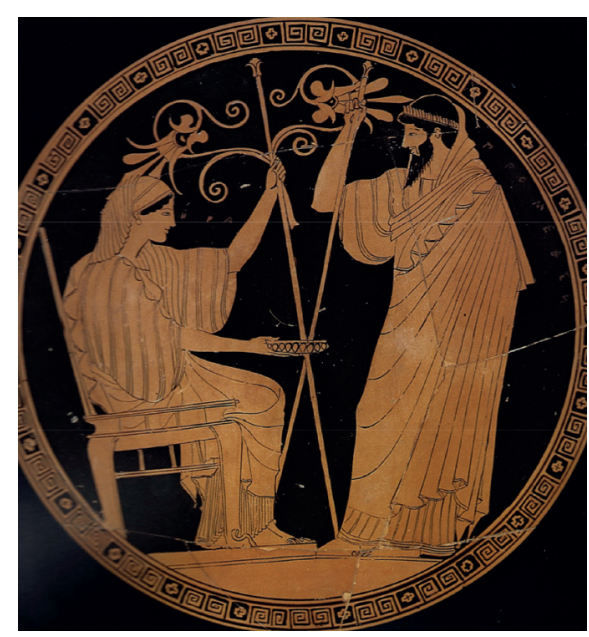

Figura 11

${ }^{38}$ Paris, Cabinet des Médailles 542 ; vers 480 av. J.-C. ; ARV² 438.133, 1653; Para 375; Add² 239; BArch 205179. ${ }^{39} \mathrm{Comme}$ le note François Lissarrague, (1999, p. 145-146) il y a une inversion des rôles dans cette image, puisqu'en règle générale c'est l'homme qui trône et tient la phiale et la femme qui le sert. 
Pour conclure : la fleur est un signe polysémique tout comme les gestes qui la portent. Au cours de cette brève étude, je me suis intéressée à la fleur qui est portée par des gestes solennels de salutation, de reconnaissance et même de réconciliation, gestes qui sont fins et modérés, souvent à peine distincts des gestes de simple démonstration. Toutefois, ces gestes arrivent à suggérer une certaine tension, une certaine dynamique entre le destinateur et le destinataire de la fleur. Cette dynamique se trouve toujours accompagnée d'un échange de regards, et fort probablement d'un échange de paroles, ceux-ci étant les signes de la volonté de s'honorer réciproquement, mais aussi des témoignages d'alliance, d'estime et même d'affection entre parents, amis et égaux. Dans certains cas, la fleur sans être portée par un geste, reste dans la logique du don, de la philia et de la charis : sous l'apparence d'un ornement de remplissage, elle est un vrai signe qui met en évidence toute l'importance de ceux-ci.

\section{Références bibliographiques:}

ALAUX, Jean. Le liège et le filet: filiation et lien familial dans la tragédie athénienne du V $\mathrm{V}^{\mathrm{e}}$ siècle av. J.-C. Paris: Belin, 1995.

AZOULAY, Vincent. Xénophon et les grâces du pouvoir: de la charis au charisme. Paris: Publications de la Sorbonne, 2004.

BENVENISTE, Émile. Don et échange dans le vocabulaire indo-européen. In: Problèmes de linguistique générale. Paris: Gallimard, 1982 [1966]. v. 1.

. Le vocabulaire des institutions indo-européennes. Paris: Éditions de Minuit, 1969. v. 1.

BRILLANTE, Carlo. Charis, bia e il tema della reciprocità amorosa. QUCC, n. 59, 1998.

HERMARY, Antoine. Images de l'apothéose des Dioscures. BCH, Paris, n. 102, 1978.

JAILLARD, Dominique. Configurations d'Hermès: une "théogonie hermaïque". Kernos, Liège, supl. 17, 2007.

KEI, Nikolina. La fleur: signe de grâce dans la céramique attique. Images Revues, n. 4, 2007 (online). . La fleur: un signe de parfum dans la céramique attique. In: BODIOU, Lydie; MEHL, Véronique; FRÈRE, Dominique (Ed.). Parfums et odeurs dans l'Antiquité. Rennes: Presses Universitaires de Rennes, 2008. p. 197-203.

. L'esthétique des fleurs: kosmos, poikilia et charis dans la céramique attique du $\mathrm{VI}^{\mathrm{e}}$ et $\mathrm{V}^{\mathrm{e}}$ siècle av. J.-C. Tese (Doutorado). 2010.

. The floral aesthetics of attic red-figured pottery: visual adornment and interplay between ornament and figure. $C V A$, Österreich, Beiheft 2. No prelo.

LAURENCE, Kahn. Hermès passe ou les ambigü̈tés de la communication. Paris: F. Maspero, 1978. LISSARRAGUE, François. Vases grecs: les Athéniens et leurs images. Paris: Hazan, 1999.

MACKAY, E. Anne. Tradition and originality: a study of Exekias. Oxford: Archaeopress, 2010.

MACLACHLAN, Bonnie. The age of grace: charis in early Greek poetry. Princeton: Princeton University Press, 1993.

MOMMSEN, Heide. Zwei schwarzfigurige Amphoren aus Athen. AK, n. 32, 1989.

SAINTILLAN, Daniel. Les "Grâces" des Grecs et la philosophie: de Platon à Hegel. Études Philosophiques, n. 4, p. 541-564, 2003.

SCHEID, Évelyne. Les usages du don chez Homère: vocabulaire et pratiques. Nancy: Presses Universitaires de Nancy, 1994. 
SCHNAPP, Alain. Le chasseur et la cité: chasse et érotique dans la Grèce ancienne. Paris: Albin Michel, 1997.

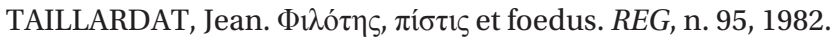

THOMSEN, Arne. Die Wirkung der Götter: Bilder mit Flügelfiguren auf griechischen Vasen des 6. und 5. Jahrhunderts v. Chr. Berlim/Boston: De Gruyter, 2011.

VERBANCK-PIÉRARD, Annie. La rencontre d'Héraclès et d'Athéna ou le regard des dieux. In: BODIOU, Lydie; MEHL, Véronique; FRÈRE, Dominique (Ed.). L'expression des corps: gestes, attitudes, regards dans l'iconographie antique. Rennes: Presses Universitaires de Rennes, 2006. VIDAL, Denis. Les trois Grâces ou l'allégorie du Don: contribution à l'histoire d'une idée en anthropologie. Gradhiva, n. 9, p. 30-47, 1991. 